\title{
Transferrin Receptor Mediated Brain Uptake During Ischemia and Reperfusion
}

\author{
Jiukuan $\mathrm{Hao}^{1}$ and Ulrich Bickel ${ }^{2}$ \\ ${ }^{1}$ Department of Pharmaceutical Sciences, University of Cincinnati. ${ }^{2}$ Department of Pharmaceutical Sciences and Center \\ for Blood-Brain Barrier Research, Texas Tech University Health Sciences Center
}

Received, May 23, 2013; Revised, August 21, 2013, Accepted, September 5, 2013, Published September 10, 2013.

\begin{abstract}
Purpose. Drug delivery by transferrin receptor-mediated transport at the blood-brain barrier has shown beneficial effects in animal models of stroke, but it is unclear whether receptor mediated uptake remains functional in the ischemic tissue. The present study addressed that question in a mouse model of brain focal ischemia, permanent or transient middle cerebral artery occlusion (MCAO). Methods. Brain accumulation of ${ }^{125}$ I-labeled 8D3, a mouse-specific transferrin receptor antibody, or of the isotype control UPC-10 used as vascular marker, was measured autoradiographically by phosphorimaging in the core ischemic region on cryostat brain sections up to $24 \mathrm{~h}$ after ischemia or reperfusion. Cerebral blood flow was quantitatively determined in the same animals after administration of ${ }^{99 m}$ Tc-ECD (Neurolite). Results. Apparent volume of distribution obtained with UPC-10 indicated no significant nonspecific leakage of the blood-brain barrier at any time point. Although brain uptake of $8 \mathrm{D} 3$ gradually declined compared to healthy tissue under MCAO, $\mathrm{V}_{\mathrm{D}}$ remained significantly higher than $V_{D}$ of UPC-10 up to $5 \mathrm{~h}$. In transient MCAO the brain uptake recovered to levels as in healthy tissue immediately after reperfusion. Conclusion. Transferrin receptor-mediated brain uptake, which is an energy dependent vesicular transport process, is sensitive to reduction in blood supply but remains partially functional for several hours after onset of ischemia. The uptake shows complete recovery after reperfusion. These results support the use of transferrin receptor-mediated brain drug delivery in the early phase of ischemia and in the phase when blood flow is restored.
\end{abstract}

This article is open to POST-PUBLICATION REVIEW. Registered readers (see "For Readers") may comment by clicking on ABSTRACT on the issue's contents page.

\section{INTRODUCTION}

The endothelial lining of brain microvessels forms the blood-brain barrier (BBB) (1). As a rule, the $\mathrm{BBB}$ prevents access to the central nervous system for $98 \%$ of small molecules and for virtually all drug candidates with a macromolecular structure like growth factors, monoclonal antibodies, or siRNA (2). However, a few exceptions to the rule form the basis of a promising physiology-based strategy to overcome the BBB. This drug delivery approach has also been labeled "molecular Trojan horse" strategy $(3,4)$, because it exploits the property of select receptors, including those for transferrin (5), insulin (6) and LRP-1 (7), to facilitate transcytosis of their physiological ligands and of engineered ligands, or of anti-receptor antibodies. Delivery by receptor-mediated transport systems has shown success in a variety of animal models of human disease, ranging from brain tumors to ischemic stroke, as recently reviewed (2, 3 ). While evidence for pharmacological effects after receptor-mediated brain delivery has been accumulating, intriguing physiological questions about the underlying cellular transport mechanism remain to be answered. One of these open questions is addressed by the present study: How does ischemia and reperfusion injury (stroke) affect receptor-mediated brain uptake? We used the murine middle cerebral artery occlusion (MCAO) model to quantify brain uptake of the transferrin receptor antibody $8 \mathrm{D} 3$ by an autoradiographic approach. Transferrin receptors are highly expressed by brain endothelial cells (8) and mediate transport of their physiological ligand $(5,9)$. Species-specific transferrin receptor antibodies, such as OX-26 for rats (10-13) and 8D3 for mice

Corresponding Author: Ulrich Bickel, M.D., Department of Pharmaceutical Sciences, School of Pharmacy, Texas Tech University Health Sciences Center, 1300 Coulter St. Amarillo, E-mail: Ulrich.Bickel@ttuhsc.edu 
$(14,15)$, serve as vectors to deliver drug moieties conjugated to the antibody into brain tissue. There is indirect evidence that transferrin receptor mediated uptake is functional under stroke conditions: Therapeutic effects have been described in both permanent and transient MCAO models in rats and mice via transferrin receptor-mediated brain targeting for neurotrophins like BDNF, FGF, GDNF, erythropoietin, and for TNF $\alpha$ decoy receptors (16-20). In these studies the drugs were administered systemically within a few hours after onset of ischemia or after reperfusion.

Interestingly, there is a hypoxia response element present in the promoter region of the transferrin receptor gene (21), and upregulation of transferrin receptors on brain endothelium has been described under conditions of chronic hypobaric hypoxia (22) and after stroke (23). However, in both reports receptor upregulation was only evaluated $24 \mathrm{~h}$ or later after the onset of hypoxia or ischemia/reperfusion injury, respectively. From the perspective of drug delivery for therapeutic purpose it may be more relevant to study time points within the first $24 \mathrm{~h}$ of an ischemic event.

\section{Materials and methods}

\section{Animal model}

All animal experiments have been approved by the institutional animal care and use committee at Texas Tech University Health Sciences Center and comply with current NIH guidelines for animal welfare. CD1 mice (female, body weight: $25 \sim 30 \mathrm{~g}$ ) were used in the present study. Anesthesia was induced by $4.0 \%$ isoflurane and maintained with 1 $1.5 \%$ isoflurane in $70 \% \mathrm{~N}_{2} \mathrm{O}$ and $30 \%$ of $\mathrm{O}_{2}$ using a face mask and a Surgivet vaporizer. Body temperature was continuously monitored by a rectal probe and temperature was maintained at $37.0{ }^{\circ} \mathrm{C}$ throughout the anesthesia and surgery by a thermostatic blanket (Harvard Apparatus, Holliston, MA, USA). Surgical procedures were performed under an OPMI Pico-i surgical microscope (Carl Zeiss, Thornwood, NY, USA) as described (24, 25). Briefly, the skull was first exposed for monitoring of local cerebral blood flow by Laser-Doppler flowmetry (Moor Instruments, Wilmington, DE, USA) using a probe positioned $1 \mathrm{~mm}$ posterior and $3 \mathrm{~mm}$ lateral to bregma. A midline incision was made in the neck to access the left carotid bifurcation and the external carotid artery (ECA), the occipital and superior thyroid arteries, and the internal carotid artery and pterygopalatine artery.
After careful preparation of the vessels, a small incision was made in the ECA, and a $15 \mathrm{~mm}$ monofilament nylon suture (6-0, Harvard Apparatus) was inserted, which had been heatrounded at the tip (head diameter: $0.2-0.3 \mathrm{~mm}$ ). The tip of the suture was advanced towards the origin of the MCA (about $9 \mathrm{~mm}$ from the carotid bifurcation) until a reduction in cortical cerebral blood flow (CBF) of the left MCA territory to less than $25 \%$ of baseline was registered by online Doppler flowmetry. For permanent occlusion the monofilament was secured in place with a ligature and the mice allowed to recover from anesthesia. For transient MCAO, the mouse was kept under anesthesia after closing the MCA, and one hour after occlusion the suture was withdrawn to allow reperfusion. Animals were excluded from the experiment if the cerebral blood flow as measured by Laser-Doppler flowmetry did not recover to at least $70 \%$ of baseline by $10 \mathrm{~min}$ post reperfusion. For post-surgical analgesia in the permanent MCAO groups, mice in the group with a survival time of $4 \mathrm{~h}$ or $24 \mathrm{~h}$ (see autoradiography experiments below) received a first dose of buprenorphine (50 $\mu \mathrm{g} / \mathrm{kg}$ ) as a subcutaneous injection, animals in the $24 \mathrm{~h}$ group received a second dose $12 \mathrm{~h}$ later. The skin incisions on the scalp and in the neck were closed with surgical clips and the animals were allowed to recover from surgery and anesthesia in their home cage until re-anesthesia for the tracer injections.

\section{Iodination of Antibody}

$\mathrm{Na}^{125} \mathrm{I}$ was purchased from NEN PerkinElmer (Waltham, MA, USA). Monoclonal 8D3 antibody was generated in serum free hybridoma culture and purified on protein G (GE Healthcare, Piscataway, $\mathrm{NJ}, \mathrm{USA}$ ). $\mathrm{IgG}_{2 \mathrm{a}}$ isotype control antibody (UPC10) was purchased from MP Biomedicals (Solon, $\mathrm{OH}, \mathrm{USA})$. Antibody labeling (40 $\mu \mathrm{g}$ of IgG and 1 $\left.\mathrm{mCi}{ }^{125} \mathrm{I}\right)$ was achieved by the Iodogen method (Pierce, Rockford, IL, USA), followed by separation from free ${ }^{125} \mathrm{I}$ over PD-10 desalting columns (GE Healthcare).

\section{Tracer for regional Cerebral Blood Flow (rCBF)}

${ }^{99 m}$ Tc-ECD (ethyl cysteinate dimer, Neurolite ${ }^{\circledR}$ ) as a marker of cerebral blood flow was provided by Lantheus Medical Imaging (Billerica, MA, USA). ${ }^{99 \mathrm{~m}}$ Tc-ECD was freshly labeled by Cardinal Health Nuclear Pharmacy Services (Amarillo, TX) on the day of experiments according to manufacturer's instructions. 


\section{Experimental design of the autoradiography} experiments

The timelines for surgery and tracer injections after either permanent or transient MCAO are depicted in Fig. $1 .{ }^{125} \mathrm{I}$ labeled antibody tracer $\left(50 \mu \mathrm{Ci}\right.$ of ${ }^{125} \mathrm{I}$ $8 \mathrm{D} 3$ or ${ }^{125}$ I-UPC-10 in $80 \mu \mathrm{L}$ physiological saline) was administered by i.v. bolus injection into the jugular vein at various time points after MCAO induction (panels A and B) or after reperfusion (panels $\mathrm{C}$ and $\mathrm{D}$ ). In the experimental groups receiving tracer injections within 5 min after MCAO induction or reperfusion, the animals were kept under continuous anesthesia (Fig 1A and 1C) until euthanasia at the end of the experiment. Mice in the experimental groups where tracer was injected after an interval of $2 \mathrm{~h}, 4 \mathrm{~h}$ or $23 \mathrm{~h}$
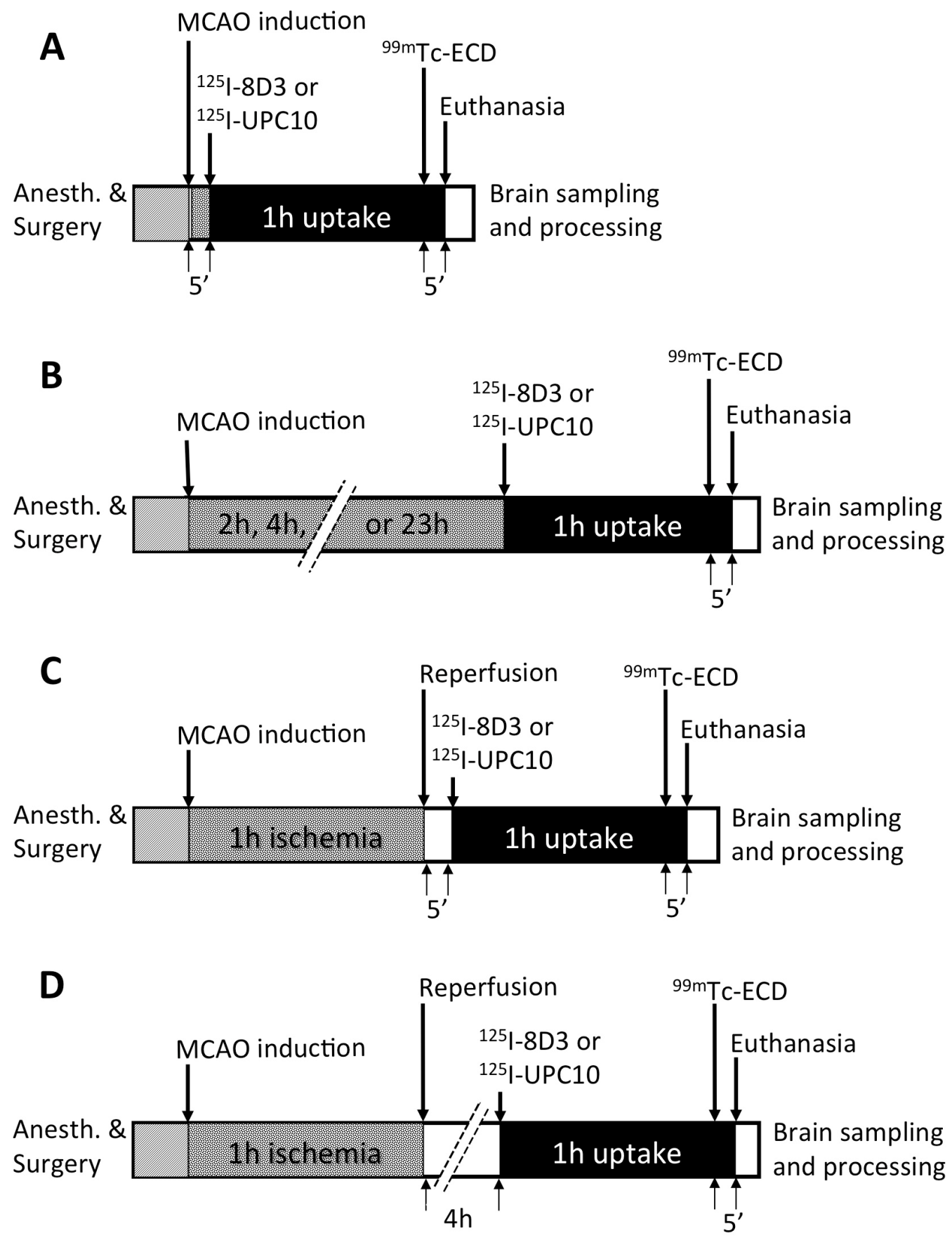

Figure 1. Experimental time lines for MCAO without (A, B) or with reperfusion (C, D). Arrows indicate the injection of antibodies (8D3 or UPC-10) and a blood flow marker ( ${ }^{125}$ I-ECD). 
(Fig. 1B and 1D, respectively) the mice were allowed to wake up and were then re-anesthetized shortly before the time point of tracer injection. In all cases the antibody tracers circulated for $60 \mathrm{~min}$ before euthanasia by decapitation for organ sampling. 5 minutes before euthanasia $(=55 \mathrm{~min}$ after the injection of ${ }^{125}$ I labeled $8 \mathrm{D} 3$ or UPC 10 antibody) the mice received an i.v bolus injection of 50-100 $\mu \mathrm{Ci}{ }^{99 m} \mathrm{Tc}-\mathrm{ECD}$ to quantify brain blood flow. A terminal blood sample was collected by cardiac puncture immediately before euthanization. A volume of $5 \mu \mathrm{L}$ of the terminal blood sample was blotted on a filter paper. Another $5 \mu \mathrm{L}$ aliquot was counted in a $\gamma$ counter. Brains were snap frozen on dry ice and $40 \mu \mathrm{m}$ brain cryostat sections were collected on glass slides and air-dried for subsequent exposure to a phosphoimager cassette.

The first scan represents a composite signal of ${ }^{99 \mathrm{~m}} \mathrm{Tc}$ ECD and ${ }^{125} \mathrm{I}$. The second scan scan represents ${ }^{125} \mathrm{I}$ signal only (8D3 or UPC-10 antibody), because the ${ }^{99 \mathrm{~m}} \mathrm{Tc}$ signal has decayed to background levels after $84 \mathrm{~h}$, which is equivalent to 14 half lives of ${ }^{99 \mathrm{~m}} \mathrm{Tc}$. Alignment of the two scans in Image $J$ followed by pixel-by-pixel subtraction of scan 2 from scan 1 yielded the ${ }^{99 m}$ Tc ECD signal representing cerebral blood flow.

Processing of the dual phosphorimaging data acquired in a $84 \mathrm{~h}$ interval was performed in NIH Image $J$ as follows:

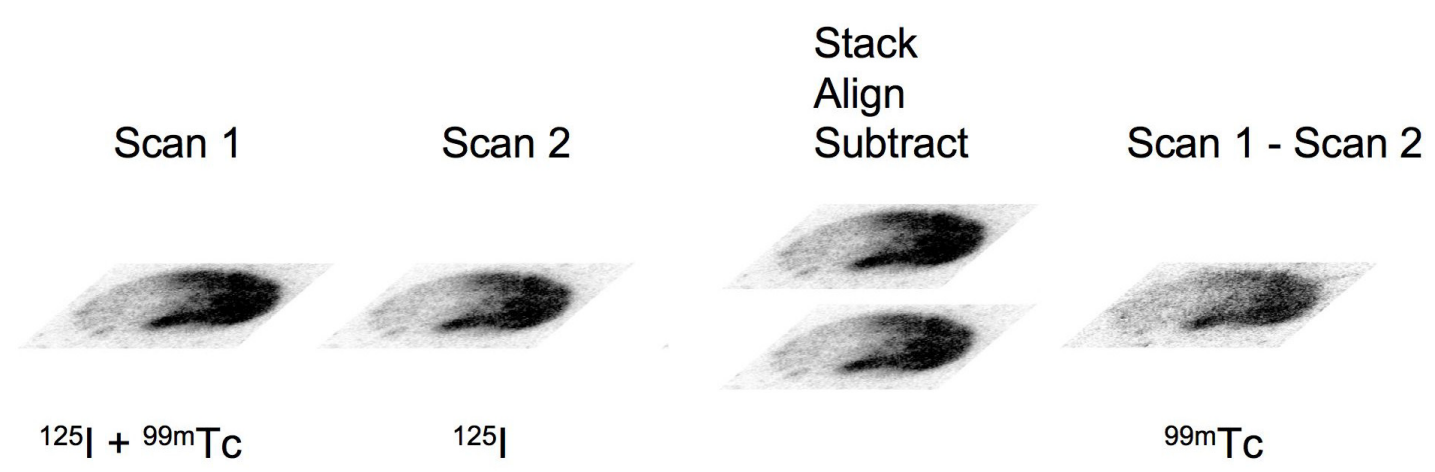

Figure 2. Processing scheme of phosphorimaging data in NIH Image J

\begin{abstract}
Autoradiography and quantitative evaluation
Brain sections on slides and blood samples on filter paper were exposed to Kodak Imaging Screen-K twice (on the day of the experiment and $84 \mathrm{~h}$ later). Autoradiographic images were acquired on a Personal Molecular Imager (BioRad, Hercules, CA, USA) at $50 \mu \mathrm{m}$ pixel size and $64 \mathrm{~K}$ grayscale resolution, and subsequently analyzed by Quantity One Software (BioRad). The absolute level of radioactivity in the autoradiographic samples was estimated by correlating the cpm values of the blood samples as measured in the gamma counter with the integrated intensity of the corresponding sample as measured by phosphorimaging.
\end{abstract}

\section{Analysis of pharmacokinetic parameters}

After obtaining the ${ }^{125} \mathrm{I}$ and the ${ }^{99 \mathrm{~m}} \mathrm{Tc}$ scans as described above, densitometry was performed in a circular region of interest (ROI) over corresponding areas of ischemic core and contralateral, healthy hemisphere. The tissue volume in the $40 \mu \mathrm{m}$ brain section over the ROI was calculated and used to estimate radioactive isotope concentration in brain tissue (cpm per gram). The apparent brain volume of distribution, $\mathrm{V}_{\mathrm{D}}$, was then calculated from the concentrations in terminal blood samples according to:

$$
V_{D}=\frac{A_{\text {brain }}}{C_{\text {plasma }}}
$$

Where $A_{\text {brain }}$ is the tracer accumulated in brain at sampling $T$ (expressed in $[\mathrm{cpm} / \mathrm{g}]$ ) and $\mathrm{C}_{\text {plasma }}$ is the terminal plasma concentration in $[\mathrm{cpm} / \mu \mathrm{L}]$.

\section{STATISTICAL ANALYSIS}

Group comparisons were performed by One-way ANOVA and Tukey's post test using GraphPad Prism 6. 


\section{ischemic hemisphere}

\section{healthy hemisphere}

Figure 3. Regions measured in the core of the stroke zone and in the corresponding healthy hemisphere

\section{RESULTS}

Brain uptake of ${ }^{125} \mathrm{I}-8 \mathrm{D} 3$ and ${ }^{125} \mathrm{I}-\mathrm{UPC}-10$ antibody were studied by autoradiography. All data evaluation was performed on $64 \mathrm{~K}$ grayscale data sets, but representative images have been processed for better visualization and are depicted in Fig.4 A F.
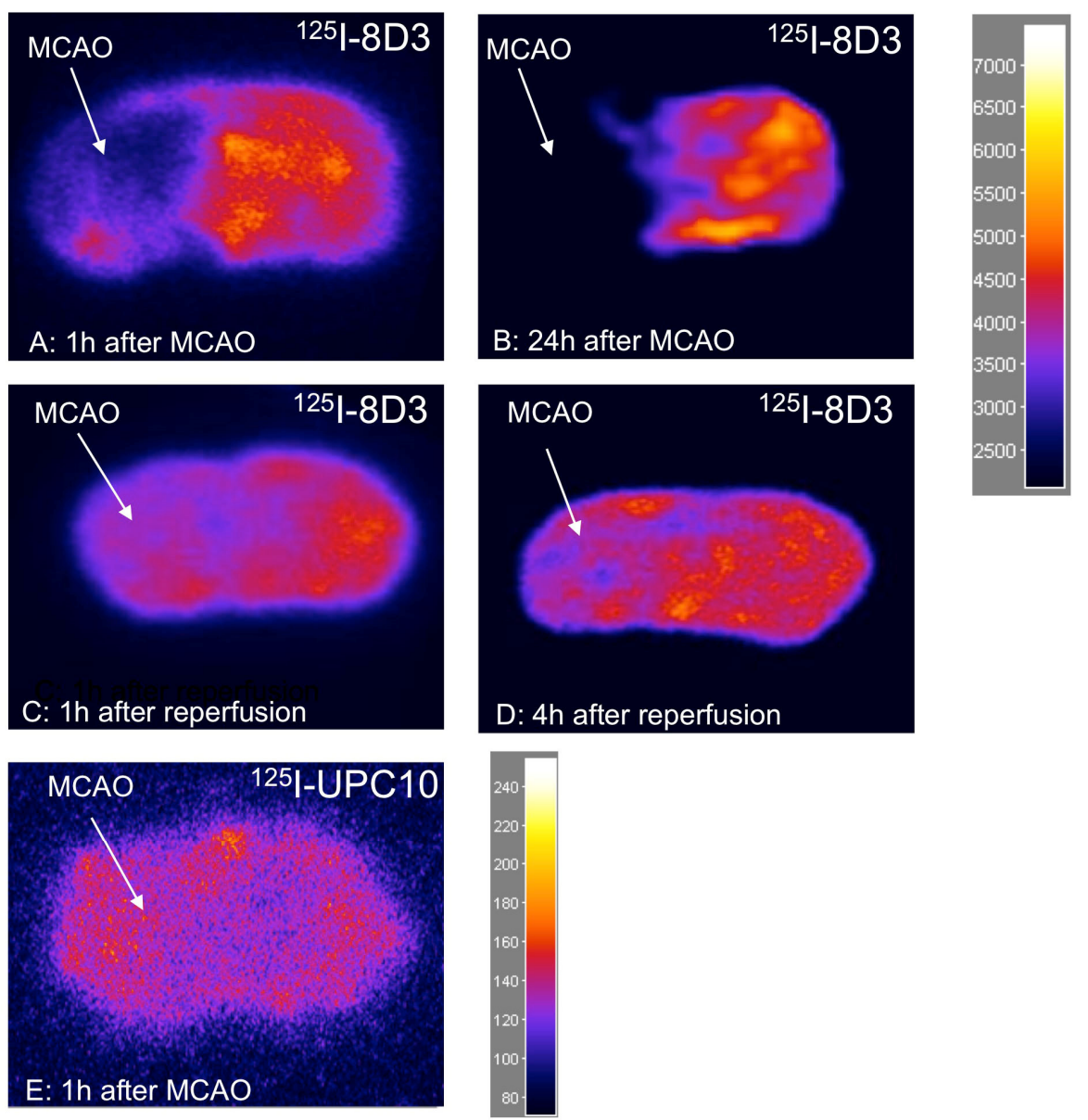

Figure 4. 8D3 or UPC 10 antibody uptake signals after MCAO.

A) 8D3 antibody uptake signals at 1 hour after MCAO. B) 8D3 antibody uptake signals at 24 hours after MCAO. C) 8D3 antibody uptake signals after 1 hour MCAO and 1 hour reperfusion. D) 8D3 antibody uptake signals after 1 hour MCAO followed by 4 hours reperfusion. E) UPC-10 antibody uptake after 1 hour MCAO. F UPC-10 antibody uptake after 1 hour MCAO followed by 4 hours reperfusion. 
For visualization, the $64 \mathrm{~K}$ intensity data as obtained from the Phosphoimager images were converted to false colors in Image J, using the same intensity setting for all 8D3 signals. Note that the intensity scale for UPC 10 signal, which is comparatively very low, was spread to allow visualization of (Fig $3 \mathrm{~F}$ ). UPC 10 signals were in the same range after ischemia in both hemispheres, for the reperfusion or the permanent occlusion model.

\section{Changes in Cerebral Blood Flow during Ischemia and Reperfusion}

Fig. 5A illustrates blood flow values in the infarct area after induction of permanent MCAO as a fraction of the contralateral (healthy) hemisphere. The values at the different time points between $1 \mathrm{~h}$ and $24 \mathrm{~h}$ post infarct ranged between 0.11 and 0.15 and were not significantly different. In contrast, there was rapid recovery of $\mathrm{CBF}$ in the infarct tissue following reperfusion after $1 \mathrm{~h}$ occlusion, as shown in Fig. $5 \mathrm{~B}$ to $80 \%$ of the values in the contralateral hemisphere.

\section{D3 Brain Uptake after Permanent MCAO}

As depicted in Fig. 6, the volume of distribution $V_{D}$ of the isotype control antibody UPC-10 remained virtually unchanged between $1 \mathrm{~h}$ and $24 \mathrm{~h}$ after permanent MCAO. UPC-10 is a vascular marker and represents the plasma space of brain tissue. The values $(12.1$ to $13.9 \mu \mathrm{L} / \mathrm{g})$ are in agreement with a value of $13.3 \mu \mathrm{L} / \mathrm{g}$ as reported by us previously for rat brain (26).
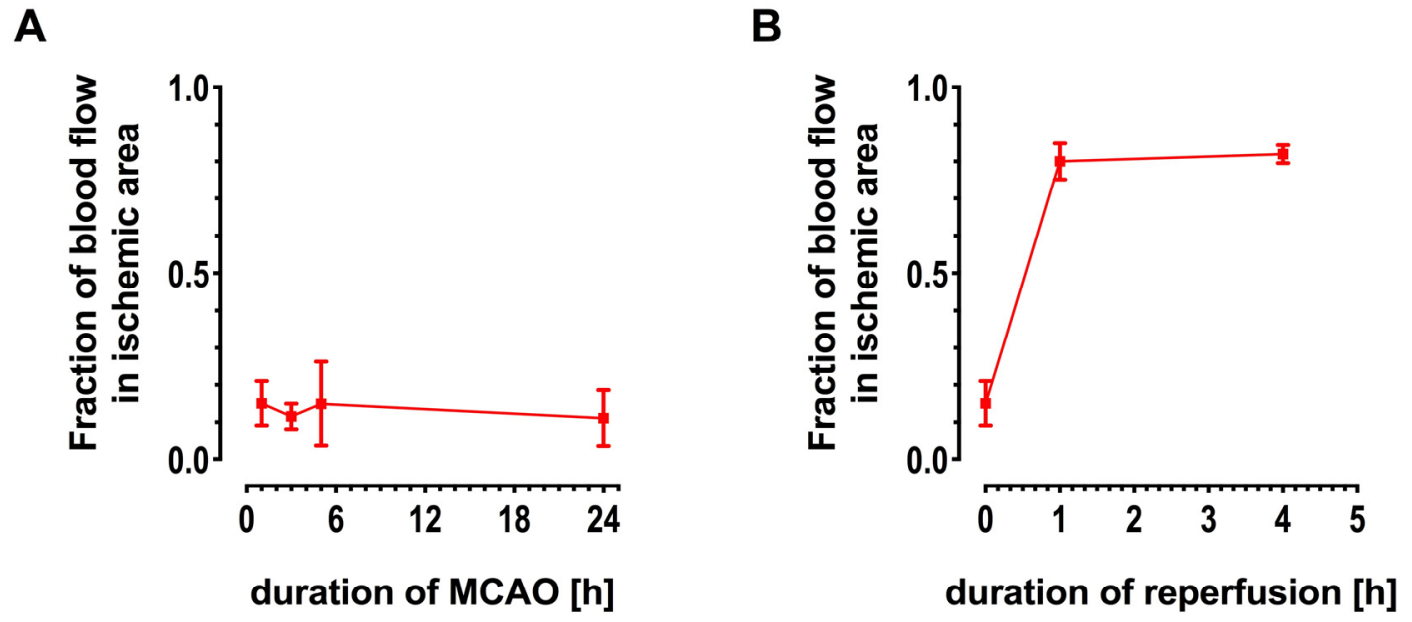

Figure 5. Reduction of blood flow after MCAO in ischemic area.

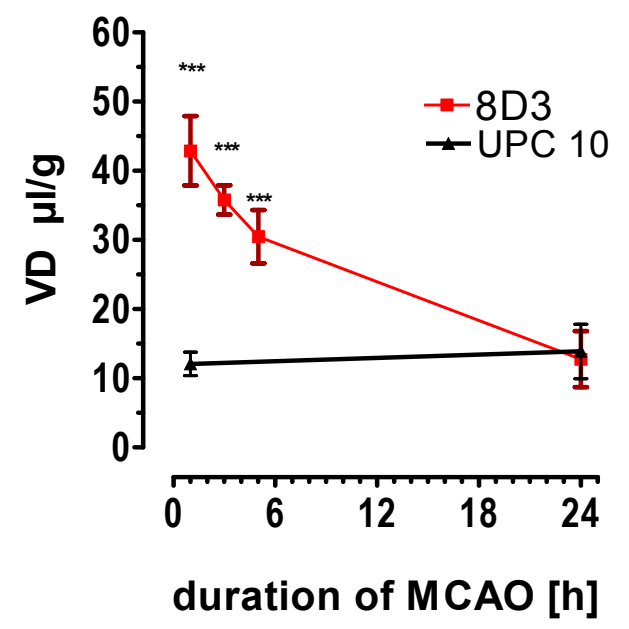

Figure 6. Time curve of apparent volume of distribution $\left(\mathrm{V}_{\mathrm{D}}\right)$ of $8 \mathrm{D} 3$ and UPC 10 antibodies, respectively, in the ischemic area after MCAO. $* * *$ indicates $\mathrm{p}<0.001 \mathrm{vs}$. value for UPC10 at $1 \mathrm{~h}$. 
8D3 undergoes binding and uptake by brain endothelial cells. This is reflected in a significantly higher apparent $V_{D}$ value. In healthy brain tissue $V_{D}$ is $232 \pm 25 \mu \mathrm{L} / \mathrm{g} \mathrm{V}_{\mathrm{D}}$ of $8 \mathrm{D} 3$ remains significantly higher than brain plasma space during the first few hours after induction of MCAO, albeit lower than in non-ischemic brain tissue and it further declines over time (from $42.9 \pm 12.2 \mu \mathrm{L} / \mathrm{g}$ at $1 \mathrm{~h}$ to $30.5 \pm$ $9.4 \mu \mathrm{L} / \mathrm{g}$ after $5 \mathrm{~h}$ ). After $24 \mathrm{~h}$ of MCAO, the $\mathrm{V}_{\mathrm{D}}$ of $8 \mathrm{D} 3$ in the ischemic core tissue is no longer different from vascular volume. This indicates that by $24 \mathrm{~h}$ there is no TfR-mediated binding or uptake by tissue in the infarct zone. When the blood flow in the infarct area is used to normalize reduced binding/uptake of 8D3 in the infarct zone vs. the healthy hemisphere (equivalent reductions of flow and uptake would result in a ratio of 1), it becomes apparent that 8D3 binding/uptake over the first hour of ischemia is reduced less than flow, while at later time points no significant deviation from a hypothetical value of 1 was found (Fig. 7).

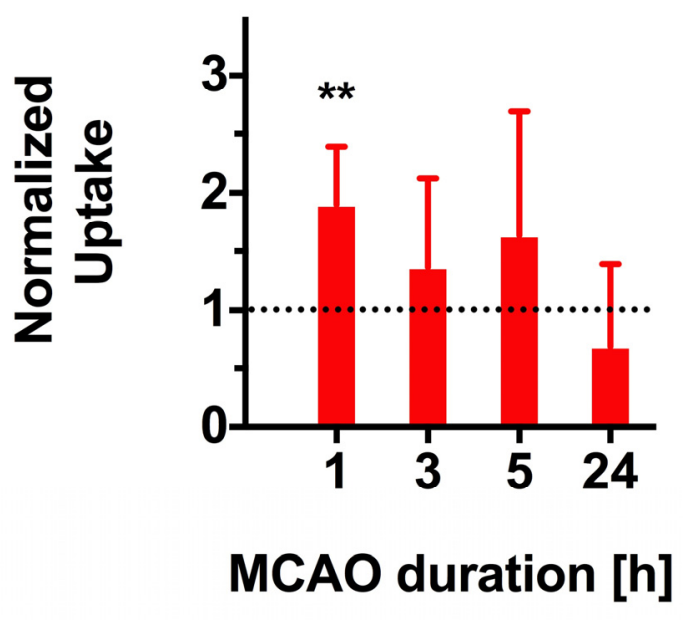

Figure 7. Brain uptake of 8D3 corrected for reduced $\mathrm{rCBF}$ after permanent MCAO. The dotted line of identity corresponds to equivalent changes in flow and antibody uptake (ratio $=1$ ) in the ischemic core relative to the healthy contralateral hemisphere. At 1 hour of ischemia, transferrin receptor-mediated binding or uptake in the ischemic brain exceeds the uptake predicted by a drop in blood flow (mean $\pm \mathrm{SD}, \mathrm{n}=6, \mathrm{p}<0.01$ by one sample $\mathrm{t}$ test vs. hypothetical value of 1.0). At all later time points there was no significant difference, i.e. brain uptake in the ischemic core was reduced analogous to $\mathrm{rCBF}$.

\section{D3 Brain Uptake after Reperfusion}

The uptake of $8 \mathrm{D} 3$ by brain tissue recovers in parallel to blood flow, as shown in Fig. 8. $V_{D}$ of the isotype control antibody in the reperfused infarct area remains low at a value of $14.5 \pm 2.5 \mu \mathrm{L} / \mathrm{g}$ at $4 \mathrm{~h}$ of reperfusion. This is not significantly different from either the $V_{D}$ value during the $1 \mathrm{~h}$ period of MCAO $(12.1 \pm 1.7 \mu \mathrm{L} / \mathrm{g})$, or the $\mathrm{V}_{\mathrm{D}}$ in the contralateral hemisphere, indicating no significant breach of the BBB for macromolecules like IgG. In comparison, both $1 \mathrm{~h}$ and $4 \mathrm{~h}$ after reperfusion the apparent volume of distribution of 8D3 reaches levels, which are not significantly different from values seen in healthy brain tissue. This result indicates that $\mathrm{TfR}$ regain their ability to mediate binding and brain uptake after ischemia reperfusion injury.

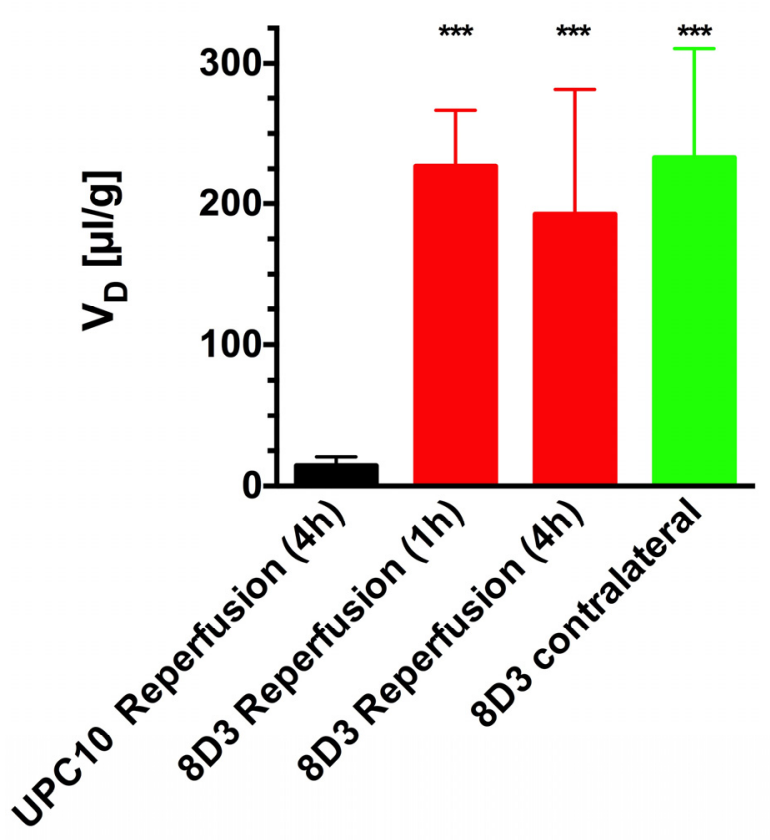

Figure 8. Volume of distribution of the 8D3 and UPC 10 antibodies in the ischemic area after MCAO. $V_{D}$ of the 8D3 antibody in the ischemic hemisphere is significantly reduced after $\mathrm{MCAO}$, and it was restored back to more than $85 \%$ of the normal value by reperfusion. Normal value of $8 \mathrm{D} 3$ antibody $\mathrm{V}_{\mathrm{D}}: 232 \pm 24.5 \mu \mathrm{L} / \mathrm{g}$. $\mathrm{V}_{\mathrm{D}}$ of the control antibody (UPC 10) remained the same at all times after MCAO and reperfusion $(13 \mu \mathrm{L} / \mathrm{g})$. Data are mean $\pm \mathrm{SD}, \mathrm{n}=6$. $* * *$ denotes $p<0.001$ vs. UPC10 (ANOVA with Tukey's post test). No significant difference between the 8D3 groups was detected.

\section{DISCUSSION}

The results of the present study permit conclusions about integrity and function of the BBB as related to the brain uptake of antibodies. First, under the experimental conditions used here, there is no significant breakdown of BBB integrity for macromolecules like IgG. Second, regarding receptor-mediated binding and uptake processes, the fate of a transferrin receptor antibody is clearly 
affected by ischemia and reperfusion: at early time points after onset of permanent MCAO, the binding/uptake of $8 \mathrm{D} 3$ is reduced, at late time points (24h) virtually abolished. However, reperfusion after MCAO leads to immediate recovery of binding/uptake.

${ }^{125}$ I-UPC-10 was used as an $\operatorname{IgG}_{2 \mathrm{a}}$ isotope control antibody. This monoclonal antibody recognizes a bacterial levan, $\beta-2-6$-linked fructosan (27) and has no known antigen specificity in mammalian tissue. It is therefore a suitable marker of vascular space in brain (26). Our data reveal the absence of overt BBB leakage in the ischemic area for this marker, which has a molecular weight of $150 \mathrm{kDa}$, for all time points after permanent MCAO and after reperfusion. While $\mathrm{BBB}$ opening to water (vasogenic edema) and low molecular weight substances is a hallmark of ischemia/reperfusion injury and frequently described to follow a biphasic pattern (28-32), leakage of macromolecules is not consistently found. For example, ${ }^{125} \mathrm{I}$-albumin (molecular weight $60 \mathrm{kDa}$ ) only showed significant increase in brain $V_{D}$ at time points later than $24 \mathrm{~h}$ after permanent MCAO in rats (33). In a mouse study where reperfusion was initiated after $60 \mathrm{~min}$ of MCAO, like in the present transient MCAO experiments, tissue uptake of Evan's Blue-albumin tracer into the striatal infarct area could only be seen in $37 \%$ and $50 \%$ of animals in the time intervals $4-8 \mathrm{~h}$ or $12-16 \mathrm{~h}$ following reperfusion, respectively (34).

With regards to the transferrin receptor antibody, the $24 \mathrm{~h}$ time point after MCAO was the only time when the apparent $V_{D}$ of 8D3 was indistinguishable from UPC-10 (Fig. 6). This finding can be readily explained by the absence of viable tissue in the striatal core area of stroke after $24 \mathrm{~h}$ of permanent ischemia, which has been documented by us and others in the mouse MCAO model with triphenyl tetrazolium (TTC) staining $(25,35)$. For the earlier sampling time points after MCAO, the apparent brain $V_{D}$ values of the transferrin receptor antibody 8D3 significantly exceeded vascular space, compatible with binding or uptake mediated by endothelial cell transferrin receptors. Our data provide strong circumstantial evidence that a major fraction of the autoradiography signal represents tissue uptake rather than receptor binding only. This conclusion is based on the following considerations: Receptor-mediated transcytosis is a regulated vesicular transport mechanism, which involves multiple GTPases and energy derived from ATP $(36,37)$. Significant depletion of ATP as a consequence of the decrease in blood flow by $80 \%$ or more would be expected to affect the transcytosis process, and this is compatible with the progressive 4-5 fold decline in brain accumulation after $1 \mathrm{~h}, 3 \mathrm{~h}$ and $5 \mathrm{~h}$ of MCAO compared to non-ischemic brain tissue, as seen here. Reperfusion after occlusion reestablishes energy supply, consistent with recovery of the brain uptake process. This is reflected in volumes of distribution in the reperfused tissue approximating values in healthy brain tissue after 1 or 4 hours of reperfusion.

While the phosphorimaging system used here allows precise quantitative measuerements over a wide dynamic range, it offers limited spatial resolution and does not allow to distinguish vascular binding, endothelial cell uptake or tissue uptake beyond the BBB. With a pixel size of $50 \mu \mathrm{m}$ resolution is on the order of mean intercapillary distance in brain (38). We plan to utilize multiphoton-imaging in live animals to address this aspect in future studies.

In conclusion, the results of the present study support the use of receptor-mediated delivery of drugs to brain tissue early after onset of ischemia and in the phase after reperfusion.

\section{ACKNOWLEDGEMENT}

The imaging agent ethyl cysteinate dimer (ECD, Neurolite $^{\mathrm{R}}$ ) was kindly provided by Lantheus Medical Imaging (Billerica, MA, USA) under PreClinical research Grant CG\#24053.

\section{REFERENCES}

1. N.J. Abbott, A.A. Patabendige, D.E. Dolman, S.R. Yusof, and D.J. Begley. Structure and function of the blood-brain barrier. Neurobiol Dis. 37:13-25 (2010).

2. W.M. Pardridge. Drug transport across the bloodbrain barrier. Journal of cerebral blood flow and metabolism 32:1959-72 (2012).

3. R. Gabathuler. Approaches to transport therapeutic drugs across the blood-brain barrier to treat brain diseases. Neurobiol Dis. 37:48-57 (2010).

4. W.M. Pardridge. Re-engineering biopharmaceuticals for delivery to brain with molecular Trojan horses. Bioconjug Chem. 19:1327-1338 (2008).

5. J.B. Fishman, J.B. Rubin, J.V. Handrahan, J.R. Connor, and R.E. Fine. Receptor-mediated transcytosis of transferrin across the blood-brain barrier. J Neurosci Res. 18:299-304 (1987).

6. K.R. Duffy and W.M. Pardridge. Blood-brain barrier transcytosis of insulin in developing rabbits. Brain Res. 420:32-38 (1987). 
7. M. Demeule, J.C. Currie, Y. Bertrand, C. Che, T. Nguyen, A. Regina, R. Gabathuler, J.P. Castaigne, and R. Beliveau. Involvement of the low-density lipoprotein receptor-related protein in the transcytosis of the brain delivery vector angiopep-2. Journal of neurochemistry. 106:1534-1544 (2008).

8. W.A. Jefferies, M.R. Brandon, S.V. Hunt, A.F. Williams, K.C. Gatter, and D.Y. Mason. Transferrin receptor on endothelium of brain capillaries. Nature. 312:162-163 (1984).

9. S. Skarlatos, T. Yoshikawa, and W.M. Pardridge. Transport of [125I]transferrin through the rat bloodbrain barrier. Brain Res. 683:164-171 (1995).

10. U. Bickel, T. Yoshikawa, E.M. Landaw, K.F. Faull, and W.M. Pardridge. Pharmacologic effects in vivo in brain by vector-mediated peptide drug delivery. Proc Natl Acad Sci U S A. 90:2618-2622 (1993).

11. P.M. Friden, L.R. Walus, G.F. Musso, M.A. Taylor, B. Malfroy, and R.M. Starzyk. Anti-transferrin receptor antibody and antibody-drug conjugates cross the blood-brain barrier. Proc Natl Acad Sci U S A. 88:4771-4775 (1991).

12. P.M. Friden, L.R. Walus, P. Watson, S.R. Doctrow, J.W. Kozarich, C. Backman, H. Bergman, B. Hoffer, F. Bloom, and A.C. Granholm. Blood-brain barrier penetration and in vivo activity of an NGF conjugate. Science. 259:373-377 (1993).

13. W.M. Pardridge, J.L. Buciak, and P.M. Friden. Selective transport of an anti-transferrin receptor antibody through the blood-brain barrier in vivo. J Pharmacol Exp Ther. 259:66-70 (1991).

14. H.J. Lee, B. Engelhardt, J. Lesley, U. Bickel, and W.M. Pardridge. Targeting rat anti-mouse transferrin receptor monoclonal antibodies through blood-brain barrier in mouse. J Pharmacol Exp Ther. 292:1048-1052 (2000).

15. Y. Zhang, Y.F. Zhang, J. Bryant, A. Charles, R.J. Boado, and W.M. Pardridge. Intravenous RNA interference gene therapy targeting the human epidermal growth factor receptor prolongs survival in intracranial brain cancer. Clin Cancer Res. 10:3667-3677 (2004).

16. R.K. Sumbria, R.J. Boado, and W.M. Pardridge. Brain protection from stroke with intravenous TNFalpha decoy receptor-Trojan horse fusion protein. Journal of cerebral blood flow and metabolism : official journal of the International Society of Cerebral Blood Flow and Metabolism. 32:1933-1938 (2012).

17. A. Fu, E.K. Hui, J.Z. Lu, R.J. Boado, and W.M. Pardridge. Neuroprotection in experimental stroke in the rat with an IgG-erythropoietin fusion protein. Brain Res. 1360:193-197 (2010).

18. R.J. Boado, Y. Zhang, Y. Zhang, Y. Wang, and W.M. Pardridge. GDNF fusion protein for targeteddrug delivery across the human blood-brain barrier. Biotechnology and bioengineering. 100:387-396 (2008).
19. B.W. Song, H.V. Vinters, D. Wu, and W.M. Pardridge. Enhanced neuroprotective effects of basic fibroblast growth factor in regional brain ischemia after conjugation to a blood-brain barrier delivery vector. J Pharmacol Exp Ther. 301:605-610 (2002).

20. Y. Zhang and W.M. Pardridge. Conjugation of brain-derived neurotrophic factor to a blood-brain barrier drug targeting system enables neuroprotection in regional brain ischemia following intravenous injection of the neurotrophin. Brain Res. 889:49-56 (2001).

21. C.N. Lok and P. Ponka. Identification of a hypoxia response element in the transferrin receptor gene. $\mathrm{J}$ Biol Chem. 274:24147-24152 (1999).

22. P. Dore-Duffy, R. Balabanov, T. Beaumont, M.A. Hritz, S.I. Harik, and J.C. LaManna. Endothelial activation following prolonged hypobaric hypoxia. Microvascular research. 57:75-85 (1999).

23. N. Omori, K. Maruyama, G. Jin, F. Li, S.J. Wang, Y. Hamakawa, K. Sato, I. Nagano, M. Shoji, and K. Abe. Targeting of post-ischemic cerebral endothelium in rat by liposomes bearing polyethylene glycol-coupled transferrin. Neurol Res. 25:275-279 (2003).

24. J. Hao, A. Mdzinarishvili, T.J. Abbruscato, J. Klein, W.J. Geldenhuys, C.J. Van der Schyf, and U. Bickel. Neuroprotection in mice by NGP1-01 after transient focal brain ischemia. Brain Res. 1196:113-120 (2008).

25. A. Mdzinarishvili, W.J. Geldenhuys, T.J. Abbruscato, U. Bickel, J. Klein, and C.J. Van der Schyf. NGP1-01, a lipophilic polycyclic cage amine, is neuroprotective in focal ischemia. Neurosci Lett. 383:49-53 (2005).

26. U. Bickel, Y.S. Kang, T. Yoshikawa, and W.M. Pardridge. In vivo demonstration of subcellular localization of anti-transferrin receptor monoclonal antibody-colloidal gold conjugate in brain capillary endothelium. J Histochem Cytochem. 42:1493-1497 (1994).

27. S. Sugii and E.A. Kabat. binding constants of levans and D-fructo-oligosaccharides to BALB/c and NZB D-fructan-specific, myeloma proteins, determined by affinity electrophoresis. Carbohydrate research. 82:113-124 (1980).

28. U. Abo-Ramadan, A. Durukan, M. Pitkonen, I. Marinkovic, E. Tatlisumak, E. Pedrono, L. Soinne, D. Strbian, and T. Tatlisumak. Post-ischemic leakiness of the blood-brain barrier: a quantitative and systematic assessment by Patlak plots. Exp Neurol. 219:328-333 (2009).

29. K.E. Sandoval and K.A. Witt. Blood-brain barrier tight junction permeability and ischemic stroke. Neurobiol Dis. 32:200-219 (2008).

30. Z.G. Huang, D. Xue, E. Preston, H. Karbalai, and A.M. Buchan. Biphasic opening of the blood-brain barrier following transient focal ischemia: effects of hypothermia. Can J Neurol Sci. 26:298-304 (1999). 
31. G.A. Rosenberg, E.Y. Estrada, and J.E. Dencoff. Matrix metalloproteinases and TIMPs are associated with blood-brain barrier opening after reperfusion in rat brain. Stroke. 29:2189-2195 (1998).

32. I. Klatzo. Pathophysiological aspects of brain edema. Acta neuropathologica. 72:236-239 (1987).

33. O. Gotoh, T. Asano, T. Koide, and K. Takakura. Ischemic brain edema following occlusion of the middle cerebral artery in the rat. I: The time courses of the brain water, sodium and potassium contents and blood-brain barrier permeability to 125Ialbumin. Stroke; a journal of cerebral circulation. 16:101-109 (1985).

34. J. Klohs, J. Steinbrink, R. Bourayou, S. Mueller, R. Cordell, K. Licha, M. Schirner, U. Dirnagl, U. Lindauer, and A. Wunder. Near-infrared fluorescence imaging with fluorescently labeled albumin: a novel method for non-invasive optical imaging of blood-brain barrier impairment after focal cerebral ischemia in mice. Journal of neuroscience methods. 180:126-132 (2009).

35. F. Liu, D.P. Schafer, and L.D. McCullough. TTC, fluoro-Jade B and NeuN staining confirm evolving phases of infarction induced by middle cerebral artery occlusion. J Neurosci Methods. 179:1-8 (2009).

36. M. Simionescu, D. Popov, and A. Sima. Endothelial transcytosis in health and disease. Cell Tissue Res. 335:27-40 (2009).

37. P.L. Tuma and A.L. Hubbard. Transcytosis: crossing cellular barriers. Physiol Rev. 83:871-932 (2003).

38. K.L. Lauro and J.C. LaManna. Adequacy of cerebral vascular remodeling following three weeks of hypobaric hypoxia. Examined by an integrated composite analytical model. Advances in experimental medicine and biology. 411:369-376 (1997). 